\title{
Management of death, dying and euthanasia: attitudes and practices of medical practitioners in South Australia
}

\author{
Christine A Stevens and Riaz Hassan Flinders University of South Australia
}

\section{Authors' abstract}

This article presents the first results of a study of the decisions made by health professionals in South Australia concerning the management of death, dying and euthanasia, and focuses on the findings concerning the attitudes and practices of medical practitioners. Mail-back, self-administered questionnaires were posted in August 1991 to a ten per cent sample of 494 medical practitioners in South Australia randomly selected from the list published by the Medical Board of South Australia. A total response rate of 68 per cent was obtained, 60 per cent of which (298) were usable returns.

It was found that forty-seven per cent had received requests from patients to hasten their deaths. Nineteen per cent had taken active steps which had brought about the death of a patient. Sixty-eight per cent thought that guidelines for withholding and withdrawal of treatment should be established. Forty-five per cent were in favour of legalisation of active euthanasia under certain circumstances.

\section{Introduction}

Advances in medical knowledge and technology in western countries enable the medical profession to exercise greater control over life and death processes, and this capacity creates a number of moral and ethical dilemmas. People may live long periods with chronic, painful, debilitating conditions which are not terminal, or not immediately fatal; while many treatments, especially those of an invasive nature, or those used to treat the severely or chronically ill, also involve some element of risk, pain, and the possibility of greater or lesser permanent damage or temporary side-effects. There is increasing tension between the aim and the ability of medicine to sustain life and the requirement to relieve suffering, and in many situations the two objectives have become incompatible. There is now considerable uncertainty about what constitute reasonable

\section{Key words}

Ethical decision-making; death and dying; euthanasia. medical standards, and there is wide divergence of opinion as to when intervention or no treatment should occur (1), and no unanimity on the moral and ethical status of decisions to forego treatment and actions taken to withdraw or terminate treatment (2). Neither is there consensus on the question of whether the deliberate termination of life should continue to be illegal in all situations $(3,4)$. Given medical ability to influence the manner and timing of death, there is growing public desire for increased participation in medical decision-making, and a recognition that it is no longer appropriate for the locus of authority in this area to be the sole prerogative of medical practitioners (5).

These issues were addressed by examining the attitudes and practices of health professionals in South Australia towards the management of death, dying and euthanasia. The research aimed, firstly, to examine whether medical practitioners and nurses were ever asked to hasten the death of patients, and the ways such requests were handled; and secondly, to investigate how medical practitioners and nurses consider such requests could be handled, and whether guidelines should be established to clarify the current legal position. This article focuses on the findings concerning the attitudes and practices of medical practitioners (6).

\section{Methods}

The list of medical practitioners registered to practise in South Australia, published by the Medical Board of South Australia, was used to obtain a ten per cent sample of 494 medical practitioners resident in South Australia. Mail-back, self-administered questionnaires were posted in August 1991. Twenty-five questions were included in the questionnaire, most of which could be answered with a tick, although five invited written responses. To maintain confidentiality the questionnaires were not marked numerically, nor were respondents required or asked to reveal their names or addresses. Two reminder/thank you letters were sent to all participants. A total response rate of 68 per cent was obtained, 60 per cent of which (298) were usable returns. 
Have medical practitioners ever suggested withholding or withdrawing treatment when discussing the options of medical treatment available to patients

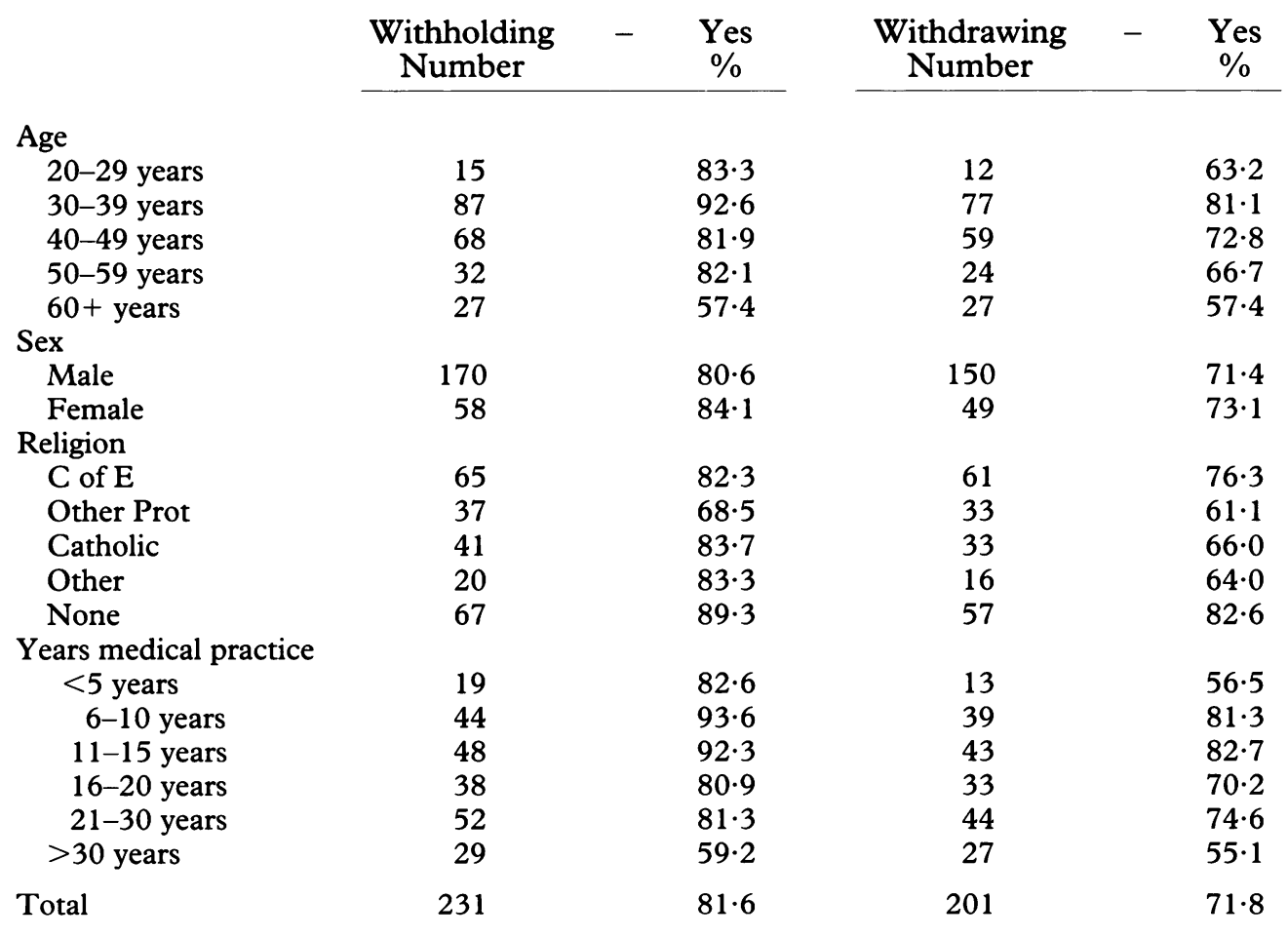

(There are a few cases missing in each category where the age, sex, religion or number of years of medical practice were not shown.)

\section{Results}

All respondents were asked if they ever received requests to hasten the death of a patient either by withdrawing treatment or by taking active steps, and whether these requests came from the patient or the patient's family. No definition of the term 'active steps' was given in the questionnaire as it was considered the meaning was implicit in the juxtaposition of the term with the phrase 'withdrawal of treatment', and that no confusion should therefore exist between passive and active euthanasia in this context.

Forty-seven per cent of medical practitioners had received a request from a patient to hasten death by withdrawing treatment, and the same proportion had received a request from a patient's family. Thirty-three per cent had received a request from a patient to hasten death by taking active steps and 22 per cent had received a request from a patient's family. Age and gender were associated with differences in request rates, with males and persons aged 29 years and under, more likely than others to have received requests. 'Persistent and irrelievable pain', 'terminal illness' and 'incurable condition', were the most frequently cited reasons for such requests.

The majority would or did discuss requests with another medical practitioner (71 per cent), nursing $\frac{7}{0}$ staff ( 63 per cent), or relatives of the patient ( 79 per cent), while lesser proportions were prepared to or $\widetilde{N}$ consulted with a religious adviser (27 per cent), a N bioethics adviser (23 per cent) or someone else (18 N per cent).

Eighty-nine per cent of respondents believed that a request to hasten death could be considered $\stackrel{0}{\circ}$ rational. Only ten per cent considered it was not, $\stackrel{\mathbb{S}}{+}$ while one per cent felt it could be considered rational under some circumstances. An open-ended question invited further explanation, and the four main reasons were given for affirmative responses - where: $\mathbb{D}$ (a) the patient suffered intractable pain and $\varrho$ suffering, (40 per cent of respondents); (b) the patient was near death or death was inevitable, $(35 \%$ per cent of respondents); (c) the patient experienced a quality of life which was extremely poor (30 perō cent of respondents), and (d) this was a matter of $\stackrel{\rightleftharpoons}{\rightleftharpoons}$ 
Table 2

Ever taken active steps which have brought about the death of a patient by age, sex and religion

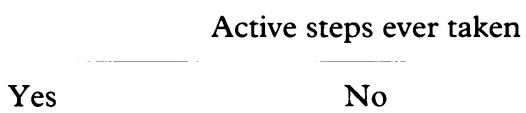

A Age

20-29 years

$15 \cdot 8$

30-39 years

$13 \cdot 7$

$40-49$ years

$50-59$ years

$60+$ years

$18 \cdot 8$

$30 \cdot 8$

$17 \cdot 5$

B Sex

Male

Female

$5 \cdot 6$

$20 \cdot 9$

$20 \cdot 7$

$\mathrm{C}$ of $\mathrm{E}$

Other Prot

$4 \cdot 0$

Catholic

Other

$16 \cdot 0$

None

$23 \cdot 7$

Total

$18 \cdot 8$
$73 \cdot 7$

77.9

$70 \cdot 6$

$59 \cdot 0$

$77 \cdot 2$

$68 \cdot 9$

$84 \cdot 7$

$65 \cdot 1$

$74 \cdot 1$

$88 \cdot 0$

$84 \cdot 0$

$68 \cdot 4$

$72 \cdot 5$
Not known

$10 \cdot 5$

$8 \cdot 5$

$10 \cdot 6$

$10 \cdot 6$

$5 \cdot 3$

$8 \cdot 6$

$9 \cdot 7$

$14 \cdot 0$

$5 \cdot 1$

$8 \cdot 0$

$7 \cdot 9$

$8 \cdot 7$

Total $A=295$

$\mathrm{B}=294$

$\mathrm{C}=295$

(Data shown in percentages)

individual freedom of choice (17 per cent of respondents).

To ascertain attitudes towards passive and active euthanasia, respondents were asked if it was ever right to bring about the death of a patient by withdrawing treatment, or by taking active steps. These questions did not define 'right' and respondents were free to interpret the meaning in a legal, moral or ethical sense. For withdrawal of treatment, 65 per cent said yes, 27 per cent said 'yes, but only if requested by the patient', while 8 per cent said it was not. For active euthanasia, 18 per cent answered yes, 26 per cent said it was 'right', but only if requested by the patient, and 55 per cent said it was not.

All respondents were asked whether, in discussing the options of medical treatment available to a patient, they had ever suggested withholding or withdrawal of treatment as possible choices (see Table 1). There were statistically significant differences in response rates for withholding treatment according to age (7) and number of years of medical practice (8).

In response to the question: 'Have you ever taken active steps which have brought about the death of a patient' which was asked of all respondents, 19 per cent said yes (56 individuals), 73 per cent said no, 6 per cent did not wish to answer, and 2 per cent were unsure. There were no significant differences in response rates according to age, sex or religious affiliation (see Table 2).

While there was a strong association between taking active steps which had brought about a patient's death and the receipt of a request, 49 per cent of those who had done so, had never received a request from a patient, and 54 per cent had never received a request from the family of a patient.

Not surprisingly, there was a strong association between taking active steps, and belief that such action was 'right'. Of all medical practitioners who had done so 50 per cent considered active steps to be 'right', and 32 per cent felt it was 'right' when requested by the patient. However, 18 per cent who had undertaken active euthanasia did not think such action was ever 'right', while ten per cent who had not, said active euthanasia was 'right', and a further 21 per cent of this group said active euthanasia was 'right' if requested by the patient.

Persons who had practised active euthanasia (56 respondents) were asked if they felt they had done the 'right' thing. Eighty-five per cent said yes, 13 per cent considered they had not, while one per cent were unsure. An open-ended question requested an explanation, and the reasons given most frequently were: (i) this action had relieved pain, suffering and distress experienced by the patient ( 42 per cent of 


\section{Table 3 \\ Suggested guidelines for withdrawal/withholding of treatment}

$\frac{\text { Medical Practitioners }}{\text { Number } \quad \% \text { Resp } \% \text { Cases }}$

Guidelines

Only on patient request

On patient and/or family request

Decision to be made by two or more doctors

Decision to be made by doctor, patient and family

Decision to be made by medical panel

Decision to be made by multi-disciplinary panel

Document all decisions

Ensure there is legal indemnity for doctor

Psychiatric assessment of patient

Patient and family to be fully informed

When patient is terminally ill

When patient has incurable disease

When patient has intractable pain and suffering

When patient is brain dead

Consider quality of life of patient

Exceptional cases to be defined

In situations where medical treatment is valueless

State the treatment to be withheld

Withdraw active treatment only

$\begin{array}{rcr}25 & 6 \cdot 5 & 15 \cdot 2 \\ 19 & 4 \cdot 9 & 11 \cdot 6 \\ 28 & 7 \cdot 2 & 17 \cdot 1 \\ 12 & 3 \cdot 1 & 7 \cdot 3 \\ 9 & 2 \cdot 3 & 5 \cdot 5 \\ 10 & 2 \cdot 6 & 6 \cdot 1 \\ 14 & 3 \cdot 6 & 8 \cdot 5 \\ 14 & 3 \cdot 6 & 8 \cdot 5 \\ 11 & 2 \cdot 8 & 6 \cdot 7 \\ 19 & 4 \cdot 9 & 11 \cdot 6 \\ 36 & 9 \cdot 3 & 22 \cdot 0 \\ 14 & 3 \cdot 6 & 8 \cdot 5 \\ 23 & 5 \cdot 9 & 14 \cdot 0 \\ 6 & 1 \cdot 6 & 3 \cdot 7 \\ 14 & 3 \cdot 6 & 8 \cdot 5 \\ 9 & 2 \cdot 3 & 5 \cdot 5 \\ 14 & 3 \cdot 6 & 8 \cdot 5 \\ 7 & 1 \cdot 8 & 4 \cdot 3 \\ 3 & 0 \cdot 8 & 1 \cdot 8 \\ & \mathrm{~N}=387 & \mathrm{~N}=164\end{array}$

(Table includes main guidelines only) (Resp=Responses; Cases $=$ Respondents)

respondents); (ii) the patient was near death (31 per cent of respondents); (iii) the situation was hopeless (31 per cent of respondents); (iv) the patient had no prospect of a meaningful or independent existence ( 15 per cent of respondents), and (v) acted on orders ( 3 per cent of respondents).

People who had not practised active euthanasia were asked if they had rejected a request because it would have been illegal. Only 16 per cent ( 40 persons) responded in the affirmative, while 38 per cent (91 individuals) said the question of legality was not a factor in their decision-making. Forty-five per cent of respondents had received no request.

To ascertain the level of awareness of current legislation in South Australia pertinent to the management of death and dying, all respondents were asked firstly, whether they were aware of The Natural Death Act, 1983 (9), and secondly, how many times in the last five years they had been presented with declarations made under this act. Seventy-two per cent were aware of the legislation, but only 24 per cent had been presented with declarations.

As the current legal position of medical practitioners who withdraw or withhold medical treatment is not clear (10), all respondents were asked if they thought 'guidelines should be established so that the legal position of medical practitioners regarding withholding and withdrawal of treatment could be clarified'. Sixty-eight per cent said yes, 18 per cent said no, and 13 per cent were? unsure. The only significant differences on this issue were between males and females, 21 per cent of the former of whom were opposed to the idea of guidelines compared with only 8 per cent of females, while 23 per cent of females were undecided compared with ten per cent of males. An open- $\frac{7}{0}$ ended question requested suggestions on what these guidelines could be, and Table 3 lists those which $N_{\sigma}$ were raised most frequently.

Attitudes towards legalisation of active euthanasian were canvassed in the question: 'Do you think it ${ }^{\mathrm{\omega}}$ should be legally permissible for medical practitioners to take active steps to bring about ac patient's death under some circumstances?'. Only $45 \stackrel{\Phi}{\Phi}$ per cent of medical practitioners were in favour of ${ }_{T}$ legalisation of active euthanasia, while 39 per cent ${ }_{0}^{-}$ were opposed. An open-ended question asked those who answered yes to indicate the circumstances, $\frac{?}{\mathbb{D}}$ which are listed in Table 4.

\section{Conclusion}

The growing tension between the dual roles ofô. sustaining life and relieving suffering has resulted in 


\section{Table 4 \\ Suggested circumstances under which it should be legally possible for medical practitioners to take active steps to bring about a patient's death}

Medical Practitioners

\author{
Number
}

$$
\% \text { Resp }
$$

$\%$ Cases

\section{Circumstances}

Terminal illness

Incurable illness

Intractable pain and suffering

Physical handicap

Mental disability

Poor quality of life

Patient request

Patient and family request

Decision of one doctor

Decision of two or more doctors

Committee decision

Decision of health team

61
38
57
10
19
24
34
21
2
10
5
3

61

38

57

10

19

24

34

21

2

10

5
3

$21 \cdot 5$
$13 \cdot 4$
$20 \cdot 1$
$3 \cdot 5$
$6 \cdot 7$
$8 \cdot 5$
$12 \cdot 0$
$7 \cdot 4$
$0 \cdot 7$
$3 \cdot 5$
$1 \cdot 8$
$1 \cdot 1$
$\mathrm{~N}=284$

$51 \cdot 3$

31.9

$47 \cdot 9$

$8 \cdot 4$

$16 \cdot 0$

$20 \cdot 2$

$28 \cdot 6$

$17 \cdot 6$

$1 \cdot 7$

$8 \cdot 4$

$4 \cdot 2$

$2 \cdot 5$

$\mathrm{N}=119$

(Table includes main circumstances only) (Resp=Responses; Cases=Respondents)

an expanding debate on what constitutes right, correct or proper medical care, especially for the terminally or severely ill. The study confirmed a lack of unanimity of opinion among medical practitioners concerning the moral, ethical and legal status of decisions to withhold or withdraw medical treatment, where the effect of these actions would be to hasten the death of a patient.

The legal ambiguity of the current situation means that patients are often subject to the ethical and moral codes of individual doctors when decisions are made, and variations are demonstrated, not only in attitudes, but in practice between individual medical practitioners in this sample. The survey revealed majority support in this sample for guidelines to be established to clarify the legal position of medical practitioners regarding withholding and withdrawal of medical treatment.

Increasingly, questions have been raised concerning the question if, and/or when it is proper in a medical, ethical or moral sense actively to terminate the lives of patients. Not surprisingly, the survey revealed considerable differences of opinion on this issue, but the evidence indicates that what many regard as reasonable or proper medical practice is in conflict with the law.

The findings also indicate that higher proportions of respondents used internalised ethical and moral values to guide their decision-making than the proportion who depended on externally imposed legal sanctions to circumscribe their actions. These and previous findings suggest, firstly, that alteration or clarification of the law would not necessarily change the practices of individual medical practitioners, and secondly, that questions of legality are currently not the principal considerations used when making decisions to withhold or withdraw treatment or to terminate the lives of patients.

The research found that there was some preparedness by medical practitioners to overlook the law and take active steps to hasten the death of their patients, and that the majority of those who had were confident they had done the right thing in the circumstances. This suggests that a minority within the medical profession perceive the law as too rigid to allow for the problems posed by individual situations, and that legality, morality and ethical behaviour are not necessarily regarded as synonymous. However, the disjunction between medical practice and the law, and individual justifications for it given by those involved, do not by themselves constitute sufficient reasons for making official changes to current codes of practice relating to active euthanasia.

Medical practitioners were divided on the question of the legalisation of active euthanasia, with considerable and almost equal minorities opposed to, or in favour of changes in the law. Among those who favoured the legalisation of active euthanasia there was some agreement that terminal illness and intractable pain and suffering constituted circumstances in which active euthanasia could or should be legal. However, there were minority opinions that poor quality of life, mental disability and physical handicap should also be valid circumstances for active euthanasia. The diversity of opinion on these issues invites caution to ensure that in framing guidelines or legislation, current abuses 
which result from the enthusiastic and aggressive pursuit of the aim of preserving life do not become transmuted into abuses due to lack of adequate protection of life.

\section{Acknowledgement}

This research was funded by the Criminology Research Council.

Christine A Stevens, Dip Soc Stud, BA (Hons), PhD, is at present a Consultant in Social Issues Research. At the time of this research she was a Research Fellow in Sociology at the Flinders University of South Australia. Riaz Hassan, $B A, M A, P h D$ is Professor of Sociology at the Flinders University of South Australia.

\section{References}

(1) Wanzer S H et al. The physician's responsibility towards hopelessly ill patients: a second look. New England journal of medicine 1989; 320, 1: 844-849.

(2) Gillon R. Euthanasia, withholding life-prolonging treatment, and moral differences between killing and

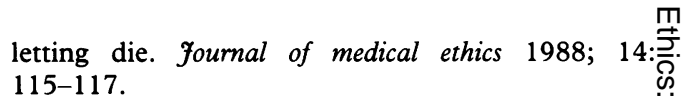

(3) Parker M. Moral intuition, good deaths and ordinary medical practitioners. Fournal of medical ethics 1990; 16: 28-34.

(4) Davies J. Raping and making love are different음 concepts: so are killing and voluntary euthanasia. $\frac{\bar{\rho}}{\bar{\alpha}}$ Fournal of medical ethics 1988; 14: 148-149.

(5) Loewy E H. Involving patients in Do Not Resuscitate (DNR) decisions: an old issue raising its ugly head.o fournal of medical ethics 1991; 17: 156-160.

(6) Complete findings of the research are reported in Stevens C A, Hassan R. Management of death, dying $\vec{\omega}$ and euthanasia: attitudes and practices of medical practitioners and nurses in South Australia. Report? prepared for the Criminology Research Council, 1992.

(7) Age, $x^{2}=25 \cdot 7, \mathrm{DF}=4, P=<\cdot 05$

(8) Number of years of medical practice, $\chi^{2}=24 \cdot 8$, $\mathrm{DF}=5, \mathrm{P}=<\cdot 05$

(9) Patients over the age of 18 years may make ano advance declaration (commonly referred to as a living. will) that extraordinary means need not be taken if $\underset{Z}{Z}$ they are terminally ill and death is imminent.

(10) Pollard B J. Withdrawing life-sustaining treatmento from severely brain-damaged persons. The medical journal of Australia 1991; 154: 559-561.

\section{News and notes}

\section{2nd World Congress of Bioethics}

The International Association of Bioethics's Second World Congress of Bioethics will be held in Buenos Aires, Argentina on October 24-26 1994.

For further information contact: Silvina Mathen, Secretaria, Escuela Latinoamerican de Bioetica,
Fundacion Dr Jose Mainetti, Calle 508e/16y 17 (1897)

MB Gonnet, Buenos Aires, Argentina.

Telephone: (021) 711160 or 6471 2616/3119; fax:

54/21/71 2222; Email: Postmast @funmai.org.ar.

\section{News and notes}

\section{Scientific (Mis)Conduct and Social (Ir)Responsibility}

The Poynter Center for the Study of Ethics and American Institutions at Indiana University will hold a one-day conference on the relationship between scientific misconduct and broader issues of social responsibility on May 27, 1994.

There is no conference fee, but pre-registration is required by April 15, 1994.

More information on the conference may be obtained by contacting Dr Kenneth D Pimple at the Poynter Centre, 410 North Park Avenue, Bloomington, Indiana 47405, phone 812-855-0261, e-mail Pimple@Indiana.edu. 